\title{
Plasma Lipid Profile and Cardiac Risk Markers in Diabetic Nephropathy
}

\author{
Nagendra Subba Rammaiah ${ }^{1}$, Praveenkumar Deverbhavi², Kashinath Rattihalli Thirumala ${ }^{3}$ \\ ${ }^{1}$ Department of Medicine, Subbaiah Institute of Medical Sciences, Shivamogga, Karnataka, India. ${ }^{2}$ Department of \\ Endocrinology, Subbaiah Institute of Medical Sciences, Shivamogga, Karnataka, India. ${ }^{3}$ Department of Research \\ and Development, Subbaiah Institute of Medical Sciences, Shivamogga, Karnataka, India.
}

\section{ABSTRACT}

\section{BACKGROUND}

Nephropathy is one of the serious diabetic complications and haemodialysis the common modality employed generally aimed to correct the altered crystalloids as well as to remove accumulated nitrogenous waste products. But it rarely corrects the vascular lipid levels, hence increasing the thrust of dyslipidaemia and dyslipidaemia induced cardiovascular complications in these patients. A study was planned to assess the cardiovascular risk factors, Cardiac Risk Ratio, Atherogenic Index of plasma and Atherogenic Coefficient in these patients to evaluate the cardiovascular risk.

\section{METHODS}

Patients of type 2 diabetes suffering from diabetic nephropathy undergoing haemodialysis at Subbaiah Institute of Medical Sciences, Shivamogga, and its affiliated hospitals in the age group of 30-60 years were randomly selected. A heparinised blood sample was collected after obtaining a written consent. Plasma lipid profile, Cardiac Risk Ratio, Atherogenic index of plasma and Atherogenic Coefficient were estimated. Aged matched non-diabetic subjects and type 2 diabetic patients without renal complications served as normal controls and diabetic controls respectively.

\section{RESULTS}

Levels of FPG, TC, TAG, HDLC, LDLC, VLDLC, CRR, AIP and AC were significantly elevated in patients of diabetic nephropathy.

\section{CONCLUSIONS}

Patients of diabetic nephropathy undergoing regular haemodialysis must be screened frequently for cardiovascular complications.

\section{KEY WORDS}

Diabetic Nephropathy. Haemodialysis, Cardiac Risk Markers
Corresponding Author:

Dr. Kashinath Rattihalli Thirumala Director,

Department of Research and Development, Subbaiah Institute of Medical Sciences, Purle, NH-13, Shivamogga-577222, Karnataka, India.

E-mail: drkashinath_1945@yahoo.co.in

DOI: $10.14260 /$ jemds/2020/116

Financial or Other Competing Interests: None.

How to Cite This Article:

Rammaiah NS, Deverbhavi P, Rao KRT. Plasma lipid profile and cardiac risk markers in diabetic nephropathy. J. Evolution Med. Dent. Sci. 2020;9(08):516519, DOI: 10.14260/jemds/2020/116

Submission 03-01-2020,

Peer Review 03-02-2020,

Acceptance 05-02-2020,

Published 24-02-2020. 


\section{BACKGROUND}

Diabetes Mellitus (DM) is a chronic metabolic complication involving nutrient metabolism in general and glucose metabolism in particular resulting in persistent hyperglycaemia and glucosuria.(1) Further this disease involves derangement in lipid turnover leading to dyslipidaemia.(2) The persistent hyperglycaemia and the DM induced dyslipidaemia are the root cause for many life threatening diabetic complications including micro and macro vascular complications. ${ }^{(3-5)}$ Nephropathy is one of the serious diabetic complication which makes the life miserable for a diabetic patient whose kidneys normal function is much affected and the patient needs frequent haemodialysis to maintain vascular fluid normalcy as well as to thrive-on. Haemodialysis is generally aimed to correct the altered blood crystalloid substances as well as to remove the accumulated metabolic nitrogenous waste products, but it rarely corrects the vascular lipid levels which tends to alter in a diabetic patient due to underlying dyslipidaemia, thus driving the diabetic nephropathic (DN) patients to dyslipidaemia induced cardio-vascular complications. Though raised levels of VLDL, LDL and triacylglycerols have been agreed as the risk factors of CVD but the significance of cardiac risk markers - Cardiac Risk Ratio (CRR), Atherogenic Index of Plasma (AIP) and Atherogenic Coefficient (AC) in DN patients have not been established. Hence a study was undertaken to assess the plasma lipid profile parameters as well as the cardio-vascular risk factor in DN patients undergoing haemodialysis.

\section{METHODS}

The present Analytical cross-sectional study was carried-out during January-April 2019 jointly by Dept. of Research and Development, Dept. of Medicine and Dept. of Diabetology, Subbaiah Institute of Medical Sciences, Purle, Shivamogga. A total number of 150 subjects including normal control subjects $(n=50)$, control diabetic subjects $(n=50)$ and diabetic with renal complications $(n=50)$ were included in the present study. The type- 2 diabetes mellitus patients, in the age group of 30-60 years and are without any diagnosed diabetic complications (as screened by expert clinical examination) attending medical outpatient department of Subbaiah Institute of Medical Sciences, Purle Shivamogga and its affiliated hospitals were randomly selected for the present study and were employed as control diabetic subjects (group2). The diabetic subjects in the age group of 30-60 years with diagnosed renal complications and are undergoing routine haemodialysis (biweekly) at the Nephrology Unit of Subbaiah Institute of Medical Sciences and its affiliated hospitals were taken as DN patients (Group-3). The age- matched normal control subjects were taken from the employees of Subbaiah Institute of Medical Sciences and its affiliated hospitals (group-1). A fasting heparinised blood sample (4-6 ml) was collected from normal control subjects (group-1), control diabetic subjects (group-2) and from the DN patients (Group3) after obtaining an informed consent from each one of them.

The blood samples were centrifuged at $3000 \mathrm{rpm}$ for $6-8$ mins and the separated clear plasma was employed for the estimation of glucose,(6) total cholesterol, triacylglycerols (TAG), $(7,8)$ and HDL-cholesterol $(9,10)$ levels. Using the data VLDL cholesterol (VLDLC), LDL-cholesterol (LDLC) levels as well as the cardio-vascular risk indicators Atherogenic Coefficient (AC), Atherogenic Index of Plasma (AIP) and Cardiac Risk Ratio (CRR) were evaluated using the following standard relations.(11-13)

- $\quad \mathrm{VLDLC}=(\mathrm{TAG} / 5)$

- $\quad$ LDLC $=($ TC - HDLC - VLDLC $)$

- $\quad \mathrm{CRR}=(\mathrm{TC} / \mathrm{HDLC})$

- $\quad \mathrm{AIP}=\log (\mathrm{TAG} / \mathrm{HDLC})$

- $\quad \mathrm{AC}=(\mathrm{TC}-\mathrm{HDLC} / \mathrm{HDLC})$

\section{Statistical Analysis}

The results were expressed as their Mean \pm SD and the statistical significance was calculated using GraphPad InStat (Version 3.10) by ANOVA.

\section{RESULTS}

A total number of 150 subjects were involved in the present study including 50 in group-1, 50 in group- 2 and 50 in group3 subjects Results obtained in the present study are depicted in table- 1 and table- 2 . Table- 1 narrates the plasma levels of glucose (Fasting plasma glucose), total cholesterol (TC), triacylglycerol (TAG), HDL-cholesterol (HDLC), LDLcholesterol (LDLC) and VLDL-cholesterol (VLDLC) in group-1, group- 2 and group- 3 . It is evident from the table that the levels of FPG, TC, TAG, HDLC, LDLC and VLDLC are significantly elevated in group-2 patients as compared to group-1, whereas except FPG all other parameters are significantly increased in group- 3 as compared to group-2 patients.

\begin{tabular}{|c|c|c|c|c|c|c|}
\hline & $\begin{array}{c}\text { FPG } \\
(\mathrm{mg} / \mathrm{dl})\end{array}$ & $\begin{array}{c}\text { TC } \\
(\mathrm{mg} / \mathrm{dl})\end{array}$ & $\begin{array}{c}\text { TAG } \\
(\mathrm{mg} / \mathrm{dl})\end{array}$ & $\begin{array}{c}\text { HDLC } \\
(\mathrm{mg} / \mathrm{dl})\end{array}$ & $\begin{array}{c}\text { LDLC } \\
(\mathrm{mg} / \mathrm{dl})\end{array}$ & $\begin{array}{l}\text { VLDLC } \\
\text { (mg/dl) }\end{array}$ \\
\hline Group 1 (50) & $\begin{array}{c}88.27 \pm \\
13.30\end{array}$ & $\begin{array}{c}168.38 \pm \\
22.25\end{array}$ & $\begin{array}{c}98.60 \pm \\
10.25\end{array}$ & $\begin{array}{c}59.92 \pm \\
9.50\end{array}$ & $\begin{array}{c}91.31 \pm \\
46.39\end{array}$ & $\begin{array}{c}20.92 \pm \\
6.30\end{array}$ \\
\hline Group 2(50) & \begin{tabular}{|l|}
$152.31 \pm$ \\
$21.80^{* * *}$
\end{tabular} & $\begin{array}{l}216.20 \pm \\
26.50^{* * *}\end{array}$ & $\begin{array}{l}218.80 \pm \\
36.60^{* * *}\end{array}$ & \begin{tabular}{|c|}
$39.90 \pm$ \\
$16.92^{* * *}$
\end{tabular} & $\begin{array}{l}98.62 \pm \\
39.25^{* *}\end{array}$ & $\begin{array}{c}44.06 \pm \\
11.38^{* * *}\end{array}$ \\
\hline Group 3 (50) & $\begin{array}{c}216.0 \pm \\
27.0 \\
\end{array}$ & $\begin{array}{l}132.62 \pm \\
18.50^{* * *}\end{array}$ & $\begin{array}{l}132.71 \pm \\
18.30^{* * *}\end{array}$ & \begin{tabular}{|c|}
$24.94 \pm$ \\
$11.50^{* * *}$
\end{tabular} & $\begin{array}{l}83.25 \pm \\
9.30^{* *}\end{array}$ & $\begin{array}{l}27.54 \pm \\
8.98^{* * *}\end{array}$ \\
\hline \multicolumn{7}{|c|}{$\begin{array}{c}\text { Table 1. Plasma Levels of Fasting Plasma Glucose (FPG), Total } \\
\text { Cholesterol (TC), Triacylglycerols (TAG), HDL-Cholesterol (HDLC), } \\
\text { VLDL Cholesterol (VLDLC), and LDL-Cholesterol (LDLC) }\end{array}$} \\
\hline $\begin{array}{ll}\text { Note } & \\
1 . & \text { The val } \\
\text { 2. } & \text { The nur } \\
\text { 3. } & \text { Probabi }\end{array}$ & $\begin{array}{l}\text { express } \\
r \text { in pare } \\
* p>0.0\end{array}$ & $\begin{array}{l}s \text { their M } \\
\text { eses indi } \\
p>0.01 \text { a }\end{array}$ & $\begin{array}{l} \pm S D \text {. } \\
\text { es the } n \\
k * * p>0 \text {. }\end{array}$ & 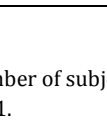 & & \\
\hline
\end{tabular}

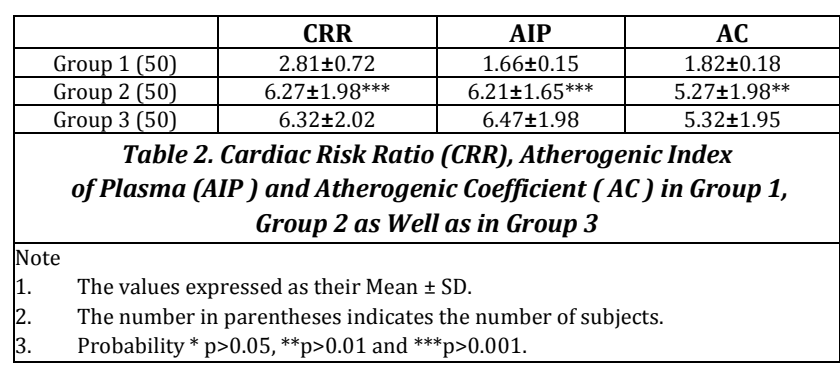

Table- 2 gives the levels of CRR, AIP and AC in group-1, group- 2 and group-3. It is clear from the table that all the three calculated parameters are significantly elevated in group- 2 and group- 3 as compared to group-1 suggesting both group-2 and group-3 patients are prone to cardio-vascular 
risk threat though they are undergoing regular haemodialysis (constant clinical supervision).

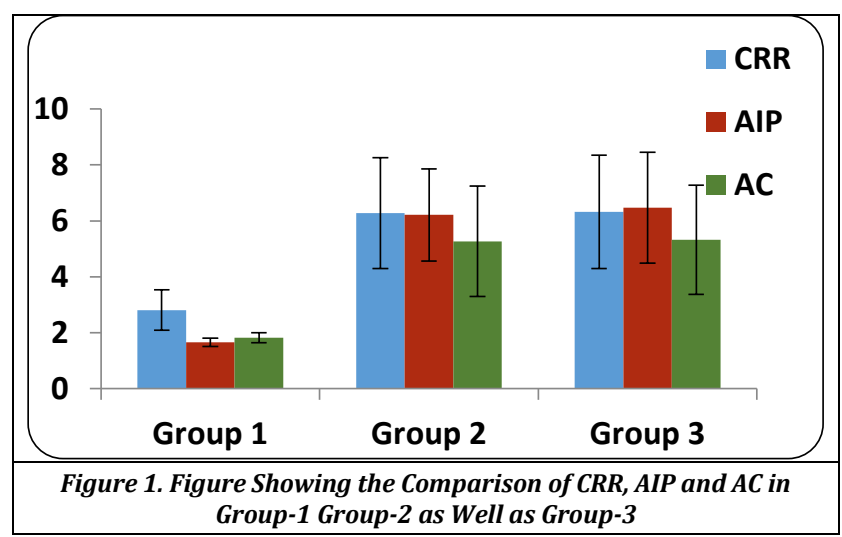

\section{DISCUSSION}

DM is a multi-systemic abnormality characterised by increased blood glucose levels (hyperglycaemia), increased blood lipid levels (hyperlipidaemia) with a prevalence to develop micro and macro vascular complications,(3-5) hence the diabetic patients are more prone to cardiovascular diseases. The more relevant pre-disposing factor of DM induced vascular complications is dyslipidaemia, an alteration in the composition and concentrations of lipid levels in the body.(14-18) The basic components of body lipids apart from free fatty acids are TAG, cholesterol and phospholipids. As the metabolism of triacylglycerols and cholesterol is much affected in diabetic condition, due to insufficient amount or insufficient functioning of hormone insulin and also due to more availability of precursor substances like Acetyl CoA, fatty acids and glycerolphosphate.(19-22) resulting in elevated formation of these basic lipid components leading to dyslipidaemia, which further results in cardio vascular complications.

Further DM is considered as a chronic inflammatory disease and normally inflammatory conditions trigger the release of cell signalling compounds like cytokines, interleukins, tissue necrotic factors and others causing alterations in systemic lipid metabolism and lipid turnover through stimulating SREBP target genes as well as by ofregulation HMG CoA educates gene.(23-29) This leads to an increase in the systemic synthesis of lipids including cholesterol which is need of inflammatory state for the extra lipid requirement. The elevation observed in cardiovascular risk indicators in group- 2 and group- 3 patients as observed in the present study (table 3) indicates these patients are more vulnerable group for the development of cardiovascular complications. Though the significance of decreased HDLC in predicting the cardiovascular risk the importance of raised plasma TAG levels as cardiovascular risk marker cannot be ignored. The development of cardiovascular complications, including atherosclerosis, is a multi-factorial process and the raised plasma lipid levels as well as dyslipidaemia are the major key factors. ${ }^{(37)}$

The two principle lipid constituents, the triacylglycerols and the cholesterol that make up the lipoproteins salient lipid transporting particles in humans. The very low density lipoproteins (VLDL) mainly transport endogenous or liver synthesized TAG whereas the cholesterol is being transported by low density lipoproteins (LDL) and High density lipoproteins (HDL). The development of cardiovascular disease is generally predicted by cardiovascular risk indicators and the principally employed risk indicators are cardiac risk ratio (CRR), atherogenic index of plasma (AIP) and atherogenic coefficient (AC). The results obtained in the present study in group-2 and group-3 patients (Table 3 and 5) indicates that risk indicators CRR, AIP and AC are significantly elevated in these patients proving that these patients are more susceptible for cardiovascular complications and specific remedial steps are necessary in considering their treatment.

It is further clear by the results depicted in table- 1 that the plasma lipid parameters are significantly lowered in group-3 patients as compared to group- 2 patients falsely suggesting that the diabetes induced dyslipidaemia in under control, but this may be due to regular haemodialysis which might have cleared many of the lipogenic precursors from the system. It is clear by the results of the present study shown in table-3 that the DN patients (group-3) are under great cardiovascular risk as indicated by the significant elevations seen in all the cardiac risk indicators (refer table-3).

\section{CONCLUSIONS}

In DN patients, plasma lipid profile parameters do not throw much light on the prediction of cardiovascular complications. In these patients, cardiac risk markers are better predictors of cardiac risk. Hence, the DN patients undergoing regular haemodialysis must be screened frequently for their plasma cardiac risk indicators in order to control the development of cardiovascular complications.

\section{ACKNOWLEDGEMENT}

The authors thank the authorities of Subbaiah Institute of Medical Sciences and its affiliated hospitals for their help and encouragement.

\section{REFERENCES}

[1] American Diabetes Association. Diagnosis and classification of diabetes mellitus. Diabetes Care 2008;(31 Suppl 1):S55-S60.

[2] Arky RA. Clinical correlates of metabolic derangements of diabetes mellitus. In complications of diabetes mellitus. Philadelphia: WB Saunders 1982: p. 16-20.

[3] Fowler MJ. Microvascular and macrovascular complications of diabetes. Clinical diabetes 2008;26(2):77-82.

[4] Dang AQ, Faas FH, Carter WJ. Effects of streptozotocin-induced diabetes on phosphoglyceride metabolism of the rat liver. Lipids 1984;19(10):738-48. 
[5] Locke S, Tarsy D. The nervous system and diabetes in Joslin's diabetes mellitus. KM Varghese Company (India), 12th edn. 1985: p. 664-85.

[6] Trinder P. Determination of glucose in blood using glucose oxidase with an alternative oxygen acceptor. Ann Clin Biochem 1969;6:24-7.

[7] McGowan MW, Artiss JD, Strandbergh DR, et al. A peroxidase-coupled method for the colorimetric determination of serum triglycerides. Clin Chem 1983;29(3):538-42.

[8] Fossati P. Estimation of serum triglyceride. Ann Clin Biochem 1969;6:24-7.

[9] Grove TH. Effect of reagent $\mathrm{pH}$ on determination of highdensity lipoprotein cholesterol by precipitation with sodium phosphotungstate-magnesium. Clinical Chemistry 1979;25(4): 560-4.

[10] Burstein MS, Scholnick HR, Morfin R. Rapid method for the isolation of lipoproteins from human serum by precipitation with polyanions. Journal of Lipid Research 1970;11(6):583-95.

[11] Friedewald WT, Levy RI, Fredrickson DS. Estimation of the concentration of low-density lipoprotein cholesterol in plasma, without use of the preparative ultracentrifuge. Clinical Chemistry 1972;18(6):499-502.

[12] Ikewuchi CJ, Ikewuchi CC. Alteration of plasma lipid profile and atherogenic indices of cholesterol loaded rats by Tridax procumbens Linn: Implications for the management of obesity and cardiovascular diseases. Biokemistri 2009;21(2):95-9.

[13] Dobiasova M. Atherogenic index of plasma [log (triglycerides/HDL- cholesterol)]: Theoretical and practical implications. Clin Chem 2004;50(7):1113-5.

[14] Raiker VG, Vickram VV, Kashinath RT. Hypolipidemic effects of diaceto-dipropyl-disulphide in alloxan diabetic rats. Global Journal of Medical Research 2012;12(5):version 1.0

[15] Bhagavath P. Lipid profile and atherogenic index of plasma (AIP) in diabetic non-smokers and smokers in coastal Karnataka. International Journal of AJ Institute of Medical Sciences 2012;1(2):93-7.

[16] Verges BL. Dyslipidaemia in diabetes mellitus: review of the main lipoprotein abnormalities and their consequences in the development of atherogenesis. Diabetes and Metabolism 1999;25(Suppl 3):32-40.
[17] Al-Qaicy AGS. Lipid profile alteration and atherogenic indices in patients with DMII. Int J Multidiscip Curr Res 2015;3:1003-6.

[18] Taskinen MR. Diabetic dyslipidaemia. Atherosclerosis Supplements 2002;3(1):47-51.

[19] Biesenbach G. Disorders of lipid metabolism in diabetes mellitus. Wiener Medizinische Wochenschrift Supplement 1989;105:9-17.

[20] Nye CK, Hanson RW, Kalhan SC. Glyceroneogenesis is the dominant pathway for triglyceride glycerol synthesis in vivo in the rat. Journal of Biological Chemistry 2008;283(41):27565-74.

[21] Jeoung NH, Harris RA. Role of pyruvate dehydrogenase kinase 4 in regulation of blood glucose levels. Korean Diabetes Journal 2010;34(5):274-83.

[22] Bandyopadhyay GK, Joseph GY, Ofrecio J, et al. Increased malonyl-CoA levels in muscle from obese and type 2 diabetic subjects lead to decreased fatty acid oxidation and increased lipogenesis; thiazolidinedione treatment reverses these defects. Diabetes 2006;55(8):2277-85.

[23] Beisel WR. Metabolic response to infection. Annu Rev Med 1975;26:9-20.

[24] Gyulai R, Kemeny L. The immunology of psoriasis: from basic research to the bedside. Orv Hetil 2006;147(46):2213-20.

[25] Oppenheim JJ, Cohen S. Interleukins, lymphokines and cytokines. In Proc. 3rd Int Lymphokine Workshop. New York: Academic Press, Inc., 1983: p. 441-6.

[26] Dinarello CA. Interleukin-1 and its biologically related cytokines. Adv Immunol 1989;44:153-205.

[27] Feingold KR, Soued M, Adi S, et al. Effect of interleukin-1 on lipidmetabolism in the rat. Similarities to and differences from tumor necrosis factor. Arterioscler Thromb 1991;11(3):495-500.

[28] Coimbra S, Oliveira H, Reis F, et al. Circulating levels of adiponectin, oxidized LDL and C-reactive protein in Portuguese patients with psoriasis vulgaris, according to body mass index, severity and duration of the disease. J Dermatol Sci 2009;55(3):202-4.

[29] Im SS, Yousef L, Blaschitz C, et al. Linking lipid metabolism to the innate immune response in macrophages through sterol regulatory element binding protein-1a. Cell Metab 2011;13(5):540-9. 